\title{
Improving the Level on English Translation Strategies for Chinese Cultural Classics
}

\author{
Fenghua Li \\ Teaching and Research Institute of Foreign Languages, Bohai University, Jinzhou, 121013, China \\ Izy8917891@163.com
}

Keywords: Chinese cultural classics; English translation; translation strategies; culture communication

\begin{abstract}
By studying the status quo of Chinese cultural classics on English translation and in-depth analysis of existing problems, the proposed improve the level on English translation strategy for Chinese cultural classics as follows: the right to select "merge point" between domestication and foreignization, from the perspective of relevance theory, focusing on the "three-way relationship" pragmatic equivalence principle, and using corpus assist in solving the problem of translation mistakes, the cultural context of globalization oriented using English with Chinese characteristics, make full use of the acquired research achievements, follow the readability and creativity as the center of the value orientation, according to the different classification of Chinese cultural classics to develop specific translation strategies, use the Western translation theory for reference to study from many angles and comprehensive range. The research objective of this paper is to enrich the theory of Chinese cultural classics translation, in order to promote Chinese culture and promote Chinese classics to the world service.
\end{abstract}

\section{Introduction}

China has a lot of classic culture to reflect the essence of traditional culture, which is to promote Chinese culture to go out and to create excellent works. China classics translation involves the intralingual translation and interlingual translation in two phases, intralingual translation use modern Chinese have an accurate understanding of the original books written in ancient Chinese, interlingual translation use English accurately and completely express modern Chinese meaning of the ancient Chinese original books. "The most important factor to determine the quality of the classics English translation is the translator's understanding of ancient prose", "understanding the original text and its cultural connotation is the primary difficulties that must be overcome every one engaged in English translation of Chinese classics translators". The research content of this paper will promote the smooth development of ancient Chinese classics translation. By rebuilding context, the translator can be translated as far as possible the original meaning of the text books in author which social, political, age and cultural background, authentic translation of the Chinese culture to foreign countries, to correct misunderstanding of foreigners for Chinese culture and the Chinese people, make the world a more accurate understanding of traditional Chinese culture, which has important practical significance to the consolidation of China's national cultural identity inherent to improve the status of China as well as world culture in the international arena. From the perspective of classics translators and disseminators, solve the strategies problem of culture classics translation level. The ultimate goal of this research project is to enrich classics translation theory, and to improve the translation level of classical Chinese classics, and put forward practical strategies, to promote Chinese culture and promote Chinese classics to the world service. 


\section{The Right to Select "Merge Point" Between Domestication and Foreignization}

Domestication is a way for the translator to move closer to the reader. In the target language or target readers as a destination, taking the expression pattern of the target language readers are accustomed to convey the original content. The translator to move closer to the target readers, translated works must be translated into a standard national language. Domestication translation will help readers better understand the translation, and enhance the readability and appreciation of translation; foreignization is a way for translator closer to the author. To attract foreign language expression, translator closer to the author, take the expression of the authors used to convey the original content, the target language culture into home. The purpose is to consider differences in national culture, preserve and reflect exotic national identity and language style specialties, for the target readers to retain the exotic. In the practice of translation, has always been faced with choices of domestication and foreignization, make the translation by choosing to find a merge point between the reader and the author close" This " merge point" from the author sometimes nearer, sometimes nearer reader, but no matter which side close, we must follow a principle: When approaching the author, not too far from the reader; close to the reader, not too far from the author. Foreignization does not interfere with the fluent translation, domestication does not lose the original thought $[1,2]$. At the same time, insisted on language forms to adopt a strategy of domestication, do foreignization process for cultural factors. In the actual translation process of domestication and foreignization should be complementary, dialectical relationship. Translation is not only converting between languages, but also cultural exchange. Intercultural translation mainly involves language translation and cultural transfer two aspects. In specific translation practice, the translator should be based on different texts, using a variety of flexible translation to deal with the cultural differences, but should retain and convey the original national characteristics, in the true sense, and be faithful to the original text. Advocating foreignizing translation, favored retaining the original language "cultural heterogeneity factor," and also does not exclude the traditional "smooth," the basic translation standards. Both domestication and foreignization have their own limitations. In the practice of translation, according to different texts and communicative situations, to achieve optimization with a variety of interpretive compensation means.

\section{Focusing on the "Three-way Relationship" Pragmatic Equivalence Principle From the Perspective of Relevance Theory}

Relevance theory holds that communication is the reasoning by the cognitive process, which is regarded as a communication process from the schematic to an inference, is a cross-cultural and cross-language from schematic to reasoning process. Translation is essentially a complex cognitive processes, complex communication processes is between the original author, the translator and the target audience. In the process of translating, the translator is a bridge to achieve successful communication between the original author and the target reader. According to relevance theory, in the translation activities, the original author, the translator and the target audience are in a certain common cognitive environment. The original cognitive ability of translator to determine the original understanding, translation is an the key factor to determine cognitive environment overlap between the original author and the target reader $[3,4]$. Therefore, the translator should try his best to communicate the primitive communicative intention of the original language according to the content of the discourse, to find the optimal relevance in the process of analyzing and choosing the context of the original language. Translation as a special way of verbal communication, translation process involves three communicator, namely author, translator and reader, this is a three-way relationship. Translation process consists of two process of "schematic-reasoning", in the first "schematic-reasoning" process, the translator is the hearer, the authors indicate communicative intention to translator, translator based on contextual information, speech and association principles, and then the reasoning communicative intention of the author; after completion of the communication process, to enter the second "schematic-reasoning" process. The identity of the 
translator is the caller, as communicator, based on the original text, the author's communicative intention understanding, as well as translations language environment and the readers' expectation estimation, indicate information to the reader, and the reader is to explain the reasoning for schematic information. Relevance theory sufficiently emphasizes the important role of the translator. According to relevance theory, translation is a three-way relationship with pragmatic equivalent translation. First, it stressed that the translator correctly cognitive author's intention and the intention of the original language; then, through comparative study of the two languages, find the differences between the original language and translated language, and correctly evaluate the readers' reading expectation, as well as consider the acceptability of the translation in the translation context. Therefore, the optimal relevance that translator strive to achieve the goal and principles of the standard translation studies, translator's responsibility is to strive to make the author's intention and readers look forward to coincide.

\section{Using Corpus Assist in Solving the Problem of Translation Mistakes}

Chinese cultural classics in translation as translation mistakes inevitably occur, there are three common [5,6]: one is functional translation errors, the translator ignores the translation function in the translation process; the second is cultural translation errors, refers to the cultural differences brought in communication, do not understand the cultural background of the target language in which language forms resulting from selection errors; third is the linguistic translation errors, is translation errors on a particular level, because translation cannot reproduce the original language decent, leading to convey the information cannot achieve the desired results. Corpus can be found and identified semantic features by conventional methods are difficult to find, study style of the text, language habits, assisted the translators to solve the problem of translation errors. So far, corpus translation studies have made significant achievements, mainly including the universality of translation, translation norms and translators style. Translation universality refers to the presence of some common language features in the translation, these features are independent of the original, "rooted in the translation activities, independent of the impact of the two languages involved in the translation process"; translation specification refers to specific social, historical, and cultural environment, the translation will be some with regular features, but these features will change with environmental laws and time change; translator's style refers to the act of translation will be mixed with some subjective factors, to confirm whether a certain expression is repeated personal preference, or accidental phenomenon, it needs the help of corpus statistics and proof. Translation is a correct understanding and creative original in another language reproduction process, can be roughly divided into understanding, expression and checking in three stages. In the understanding stage, translation corpus can help translators to determine the original lexical semantic rhyme, author semantics rhyme and original style, thereby improving the accuracy of understanding, provide premise and guarantee for the faithfulness; at the stage of expression, by corpus to retrieve platform synonym, synonyms, collocations, sentence comparison, and others, translator get a lot of reference words, statements and expressions, so that the translation output is more accurate; in checking stage, to make quantitative analysis on the translation, through the data comparison found that the deficiencies and embellished and perfect.

\section{The Cultural Context of Globalization Oriented Use English With Chinese Characteristics}

In the context of globalization, Chinese-English translation is not a simple conversion, but a cultural exchange activity. Cultural translation is to examine the translation in the big context of cultural studies, that is, the study of the common and individual characters of the culture and the "surface" and the "deep" structure among different cultures of different nations. To explore the internal relations and the objective laws between culture and translation. In the context of globalization, the purpose of translation is not only the transmission of information, more importantly, cultural exchange and dissemination. In Chinese-English translation, to continue to build, improve and perfect description of Chinese society, culture and language of English vocabulary and expressions, 
to retain Chinese characteristics, promote the Chinese culture. English with Chinese characteristics in addition to the international English-based, but also has personality characteristics of Chinese culture and Chinese language, mainly used to describe and translate Chinese culture's unique things and phenomena, expressing unique Chinese ideas. It shows that China is different from other countries' international standpoint, viewpoint and statement, in order to safeguard the dignity and interests of the Chinese people. The specification of English with Chinese characteristics, mainly from Chinese and English bilingual skilled people to describe the English text of Chinese society, as well as literary works created by Chinese people in English, and English text model from modern Chinese official media, mainstream connotation from modern media. English with Chinese characteristics requires Chinese names and place names with standardized pinyin spelling. Specific translation strategy is as follows: First, based on the thinking of dialectical analysis, a correct understanding of the cultural translation impact on cultural transmission and cultural identity in the context of globalization, the use of constructivist translation theory to promote the dissemination and exchange of translation; then, in the current economy, under the background of cultural globalization, in line with the purpose of promoting exchanges between different cultures, to overcome Western centrism and thought of English hegemony [7,8]. In dealing with cultural factors, as far as possible foreignization translation strategy, introduction and dissemination of Chinese culture, while maintaining the original appearance of Chinese culture; and finally, the formation of English with Chinese characteristics in the East-West intercultural communication played a role in media and bridges, and to the use of English with Chinese characteristics, to spread the Chinese civilization.

\section{Make Full Use of the Research Achievements That Chinese Cultural Classics Translation has Achieved}

Characteristics of Chinese classics in translation studies is obvious, both on the traditional view of the excavation, but also an international perspective $[9,10]$. The current research is mainly reflected in two aspects: First, the research and application of "convey the look and express the meaning" ideas. "Convey the look" important that likeness, is to convey the original look. "Express the meaning" is the expression of the original meaning, especially deep meaning. Translation is the literal conversion process, the purpose is "express the meaning", in the "express the meaning" basis to achieve "convey the look" into a higher level, from the "express the meaning" to "convey the look" is regarded as translated from lower to higher development process . "Express the meaning" is the goal, is the minimum requirement of translation; "convey the look" is from the form of language requirements, "convey the look and express the meaning" is the relationship between form and content, the two are indivisible unity. Only the "express the meaning" no "convey the look", will result in translation jerky; if only "convey the look" no "express the meaning", it will cause the lack of translation on the "faithfulness". Therefore, the "convey the look" and "express the meaning" in translation cannot be separated, forming an organic unity, and pointed out the direction for the translation. Second, is the inheritance and development of "faithfulness, expressiveness and elegance" standard. The translation theory of "faithfulness, expressiveness and elegance" has opened up a stage for the further study of modern translation. "Faithfulness" is the basis of the translation, "expressiveness" is the purpose of the translation, and "elegance" is the clothing of translation. "Faithfulness" is the "honesty" relationship between the original and the translation, "keep the original content" is basic rules in the translation practice. In the process of translation, the translator should try to use real, accessible language to express the original meaning. "Expressiveness" is a thought reconstructed, is original in thought and mood expressed with exact words. "Elegance" is the translation as an art creation, is a process as faithfully as possible to reproduce the original style.

\section{Follow the Readability and Creativity as the Center of the Value Orientation}

Readability is generally regarded as the most basic standard to measure the quality of the translated 
classics. From a professional perspective, readability refers the degree of readable of translations, including [11]: the translation whether is in line with grammatical norms, compliance with customary usage, has stylistic adaptability, ideographic clear and rational. According to the above points will be able to determine the degree of readability of a translation. Readability is divided into the following levels: the best readability, general readability, basic readability and non readability. Generally, original language readable is strong, so the translator is easy to reach with a fluent, smooth target language in the translation to express the ideological content of the original. Readability center orientation of translation is mainly from the perspective of the reader. To achieve readability of classics translation, the translator must target language country customs and culture have a good understanding of their language proficiency. From the traditional sense, in the process of translation translators tend to translation fidelity in the most important position. So, whether the translation process need to creativity or not? The purpose of the translator in the target language performed better creative translation is faithful to the original languages. In theory, formal equivalence does not mean that it is true, and formal asymmetry is not equivalent to betrayal. Translation is an art, is a literary creation, and in the creative process usually works in one language in another language to create. Because of implicit and ambiguity characteristic of literature itself, it is often stressed that the faithful translation often leads to the text of the target language to be difficult to understand. Therefore, translation is a re-created process, is the unity of opposites of faithfulness and creativity.

\section{According to the Different Classification of Chinese Cultural Classics to Develop Specific Translation Strategies}

To translate the different genres of classics, require different translation strategies, the flexibility to use various translation methods and techniques. Chinese classics are rich, literature, history and philosophy, and other classics in the majority. The English translation of classics should follow the principle that, in order to smooth contemporary English express the spirit of the original work, and to reproduce the artistic style of the original. On the basis of the possible reception of the English reader, it is possible to translate the literal translation, that is, with the corresponding word or structure to translate the original [12]. In the presence of words do not convey or misleading, to take flexible approach. Even though the same concepts and terminology may appear in different ways, in a different wording is also possible to use different means of expression. When in individual cases, a simple sentence translation cannot express all the meaning, the use of interpretative translation method. This is more desirable than a lot of charging, the reader does not have to break the idea to stop reading notes. In addition, the impact is difficult to understand the characters and understand the story, can be used in the method of virtual. In view of the language characteristics of Chinese classics, such as concise, rich in content, not hypotaxis and parataxis, and others, the translator should flexibly using various translation methods and techniques, including the "literal translation, free translation, transliteration, explanatory translation, specific, generalized treatment, gain, reduction, flexible, compensation, use note, use a variety of translation methods", and others, on the basis of a comprehensive and thorough understanding the original, smoothly and faithful interpret the ideological and cultural connotation of the classics.

\section{Use the Western Translation Theory for Reference to Study From Many Angles and Comprehensive Range.}

The cultural turn, which is proposed by the cultural school, indicates a close relationship between translation and culture. Therefore, we can use the intercultural communication theory and the mass communication theory, to study the translatability of cultural schemata in Chinese ancient classics, and to explore the guiding significance of the translation theory proposed by the cultural school for classic English translation. It is considered that the double attributes of the theory and application to describe translation theory, highlighting the importance of context and context in the translation practice, promoting both consider the text and behavior, but also consider the cultural background. 
German functionalist put forward about translation is a kind of behavior and purpose behavior theory, can help translators in the conduct of classics translated into English priority to functional characteristics rather than the principle of reciprocity, and focus on the specific translation requirements.

\section{Conclusion}

English translation of Chinese classics has made great achievements, but also faces many problems, mainly reflected in: the selection is more simple, mostly concentrated in the classical literature, and some even have multiple translations, but many nonfiction books and ancient books in ethnic minority languages are not is translated; the theory divorce from practice, most classics into English practitioners not engaged in theoretical research, theoretical researchers basically does not engage in the practice of translation; lack of effective external communication channels, Chinese classics into English translation world full of aspirations to the world, and the Chinese translation who presided over the release of Chinese classics into English translation works and influence abroad is unsatisfactory; translators talents need to enrich, for most senior experts in the classics into English translation gradually into old age, the team of Chinese classics translators emerged fault phenomenon; cooperation and exchange needs to be strengthened, the translator's translation of overseas mainly issue in the overseas and domestic translators are mainly issued in China, lack of communication with each other. Strategies proposed to these questions provide a solution ideas and methods, which is of great significance for improving the English level of Chinese classics and promoting the spread of Chinese culture.

\section{Acknowledgement}

This work is supported by social science fund project of Liaoning province (L15BWW004): Improving the Strategy of English Translation Level for Chinese Cultural Classics.

\section{References}

[1] X. Bing, "Cultural transformation strategy in translation: domestication, foreignization and optimization," Academic Exchange, vol. 23, no. 8, pp. 144-145, 2007.

[2] Baidu Encyclopedia, "domestication and foreignization," http://baike.baidu.com/link?url=K_gXBCKjEsxVK_zFLNVEXGaP1izBg7vTOv0d3sEuvjnM_ Oq8Z8iUYkomnq2CAuPXXGMz68y5DQozpUGrp4_NKa, 2015-11-20.

[3] L. Y. Huang, F. Q. Sun, "Translation strategies of metaphor from the perspective of relevance theory," Guizhou Culture and History, vol. 32, no. 3, pp. 84-88, 2011.

[4] G. F. Yu, "On the Translation Strategies from the Perspective of Relevance Theory," Journal of University of Shanghai for Science and Technology (Social Sciences Edition), vol. 33, no. 2, pp. 111-115, 2011.

[5] X. M. Wang, "Study of Translation Errors in Scientific Paper C/E Translation based on Skopostheorie," Northwest Medical Education, vol. 21, no. 4, pp. 773-777, 2013.

[6] G. L. Yu, “Applications of Corpus in Translation Studies,” Foreign Language and Literature, vol. 26, no. 2, pp. 117-121, 2010.

[7] X. Y. Qi, "Translation strategies of promoting Chinese culture in the context of globalization," Henan Social Sciences, vol. 16, no. 5, pp. 18-20, 2018.

[8] Y. Y. Fu, "Conveying the Meaning in its Full Flavor - Towards the Construction of the Theoretical System of Translating Chinese Classics into EnglishDetailed on Oracle database architecture," Doctor's degree of Soochow University, 2011.

[9] Y. He, "Translation thought of 'conveying the spirit and meaning': Take English translation 'Drink' (fifth) of Wang Rongpei as an example," Journal of Chifeng University (Philosophy and Social Science Chinese Edition), vol. 35, no. 6, pp. 212-214, 2014. 
[10] F. R. Li, "Contrastive Analysis on 'Faithfulness, Expressiveness and Elegance' and Western Translation Theories," Journal of Changchun Normal University, vol. 33, no. 6, pp. 96-97 2014.

[11] C. H. Lu, Y. Yang, "On English Translation Strategies of Chinese Classics: A Case Study of A Visit to the Baiyue Mountain," Journal of Heze University, vol. 36, no. 6, pp. 117-121, 2014.

[12] H. Wang, "English translation of Chinese classics: Achievements, problems and solutions," Foreign Language Learning Theory and Practice, vol. 32, no. 3, pp. 9-14, 2012. 